\title{
Desquamative interstitial pneumonia associated with chrysotile asbestos fibres
}

\author{
Jeffrey A Freed, Albert Miller, Ronald E Gordon, Alf Fischbein, Jerome Kleinerman, \\ Arthur M Langer
}

\begin{abstract}
The drywall construction trade has in the past been associated with exposure to airborne asbestos fibres. This paper reports a drywall construction worker with 32 years of dust exposure who developed dyspnoea and diminished diffusing capacity, and showed diffuse irregular opacities on chest radiography. He did not respond to treatment with corticosteroids. Open lung biopsy examination showed desquamative interstitial pneumonia. Only a single ferruginous body was seen on frozen section, but tissue examination by electron microscopy showed an extraordinary pulmonary burden of mineral dust with especially high concentrations of chrysotile asbestos fibres. This report emphasises the need to consider asbestos fibre as an agent in the aetiology of desquamative interstitial pneumonia. The coexistent slight interstitial fibrosis present in this case is also considered to have resulted from exposure to mineral dust, particularly ultramicroscopic asbestos fibres.
\end{abstract}

Desquamative interstitial pneumonia (DIP) was described by Liebow et $a l^{1}$ as an idiopathic form of interstitial pneumonitis characterised by intraalveolar collections of cells. These cells were originally believed to be desquamated alveolar epithelial cells but were subsequently recognised as large reactive alveolar macrophages. ${ }^{12}$ The name desquamative has nevertheless been retained to categorise this interstitial pneumonitis because this

Department of Pathology, Mount Sinai Hospital

J A Freed, R E Gordon, J Kleinerman

The Pulmonary Laboratory, Division of Pulmonary Disease, Mount Sinai Hospital, New York

A Miller

Division of Environmental and Occupational Medicine, Mount Sinai School of Medicine of the City University of New York

A Fischbein

Environmental Sciences Laboratory, Institute of Applied Sciences, Brooklyn College of the City University of New York, NY 11210

A M Langer pathological pattern was associated with a better prognosis, a more consistent response to steroid treatment, and longer survival. ${ }^{1}$ No single specific aetiology has been determined for DIP.

The case presented here provides evidence that inhalation of mineral dust, including high concentrations of asbestos fibre, may produce the tissue reaction patterns of DIP as well as the more characteristic interstitial pulmonary fibrosis. This represents, to our knowledge, the first reported case of DIP in which the presence of asbestos fibre has been confirmed by tissue study. The analysis showed that although over $90 \%$ of the 820 million fibres/g of wet lung tissue were $3 \mu \mathrm{m}$ or less in length, sufficient numbers of fibres greater than $5 \mu \mathrm{m}$ in length were present, which could also account for the tissue response. These unusual findings prompted our detailed study and reporting of the apparent relations among asbestos fibre, DIP, and interstitial fibrosis.

\section{Case report}

The patient was employed in drywall construction for 32 years when he was exposed to components of

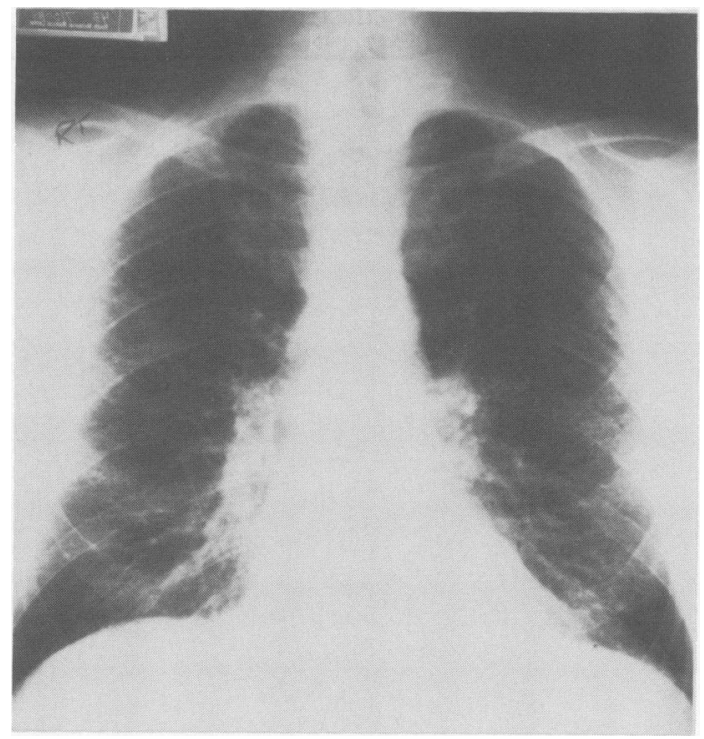

Figure 1 Pre-treatment posterior-anterior chest radiograph showing bilateral fine interstitial opacities. 
Table 1 Results of pulmonary function tests

\begin{tabular}{|c|c|c|c|}
\hline & 7 August 1985 & 14 February 1986 & 22 January 1987 \\
\hline 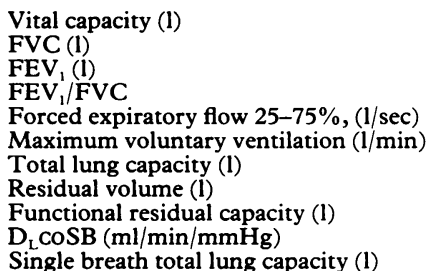 & $\begin{array}{l}4 \cdot 20(88)^{\star} \\
3 \cdot 86(81) \\
2 \cdot 66(76) \\
0 \cdot 69 \\
1 \cdot 91(55) \\
103(89) \\
7 \cdot 51(102) \\
3 \cdot 31(127) \\
4 \cdot 31 \\
137(55) \dagger \\
5 \cdot 63\end{array}$ & $\begin{array}{l}4 \cdot 00(84) \\
2 \cdot 76(80) \\
0 \cdot 69 \\
1 \cdot 67(48) \\
120(104) \\
\\
\\
13 \cdot 5(55) \\
5 \cdot 65\end{array}$ & $\begin{array}{l}4 \cdot 41(93) \\
4 \cdot 52(96) \\
2 \cdot 83(83) \\
0 \cdot 63 \\
1 \cdot 45(42) \\
124 \quad(109) \\
9 \cdot 12(124) \\
4 \cdot 71(178) \\
5 \cdot 36 \\
10 \cdot 6(44) \\
8 \cdot 14\end{array}$ \\
\hline
\end{tabular}

*Values in parentheses are percentages of predicted values

†Predicted values for $D_{L} \operatorname{coSB}$ are adjusted for smoking habit (current smoker).

taping and jointing compounds. Both mineral components of these formulations, and exposure to asbestos during sanding and finishing, have been previously reported. ${ }^{3}$ The patient was first evaluated at Mount Sinai Hospital on 7 August 1985 (aged 52) because of dyspnoea of three months duration, wheezing, and productive morning cough; he was short of breath on climbing one flight of stairs or walking one block. He smoked three packs of cigarettes a day and had been an alcoholic until two years before evaluation. Previous illnesses included hypertension, acute myocardial infarction in 1978, duodenal ulcer, and microscopic haematuria and albuminuria first noted in 1983.

Physical examination was unremarkable except for raised blood pressure $(150 / 100 \mathrm{~mm} \mathrm{Hg})$ and occasional ventricular premature beats. Chest radiographs showed fine interstitial opacities throughout both lungs, coded on the International Labour Office scale as $S / P, 1 / 2$ (fig 1 ), prominent hila, old rib fractures on the left, flattened hemidiaphragms, and increased retrosternal airspace on lateral view. The interstitial markings had progressed since 1983. There were no pleural abnormalities. A chest $x$ ray film taken in connection with a clinical field survey of drywall construction workers in 1973 showed no interstitial markings.

Results of routine laboratory tests included the following abnormalities: haemoglobin $17 \cdot 7 \mathrm{~g} / \mathrm{dl}$, uric acid $8 \cdot 2-10 \cdot 5 \mathrm{mg} / \mathrm{dl}$, cholesterol $375-466 \mathrm{mg} / \mathrm{dl}$, albumin $2 \cdot 8-3 \cdot 0 \mathrm{~g} / \mathrm{dl}, 25-30 \mathrm{red}$ blood cells/high power field on urinalysis with $4+$ albuminuria and $3.1 \mathrm{~g}$ protein $/ 24 \mathrm{~h}$. The blood urea nitrogen and creatinine concentrations, serum electrophoresis, antinuclear antibody, and latex fixation test were normal. Gallium scan showed a large area of slightly increased activity in the chest. A Kveim-Siltzbach test for sarcoidosis was negative.

Pulmonary function studies (table 1) showed normal lung volumes (vital capacity $88 \%$ of predicted) with slight airway obstruction (forced expiratory volume in one second/forced vital capacity $\left(\mathrm{FEV}_{1} /\right.$ FVC) 0.69). The single breath carbon monoxide diffusing capacity $\left(\mathrm{D}_{\mathrm{L}} \mathrm{COSB}\right)$ was moderately reduced (55\% of the smoking specific predicted value ${ }^{4}$ and the $\mathrm{PaO}_{2}$ was normal at rest. The alveolar arterial $\mathrm{O}_{2}$ difference $\left(\mathrm{A}-\mathrm{a} \mathrm{Po}_{2}\right)$ was 13 torr at rest and increased to 37 torr at maximum exercise, a value which is probably within normal limits. The excessive ventilation and dead space ( 0.48 at rest) were considered

Table 2 Results of incremental exercise testing

\begin{tabular}{|c|c|c|}
\hline & 15 October 1985 & 22 January 1987 \\
\hline Maximum ventilation $\left(\mathrm{V}_{\mathrm{E}} ; 1 / \mathrm{min}\right)$ & $114(104)^{\star}$ & $110(91)$ \\
\hline$\underset{(\mathrm{ml} / \mathrm{kg} / \mathrm{min})}{\operatorname{Maximum} \text { oxygen consumption } \mathrm{VO}_{2}(1 / \mathrm{min})}$ & $27.12(85)$ & $2 \cdot 36(94)$ \\
\hline Maximum heart rate (beats/min) & $130(77)$ & $127(75)$ \\
\hline Maximum work rate $(\mathrm{Kpm})$ & 747 & 551 \\
\hline Watts & 122 & 90 \\
\hline Dead space/tidal volume, rest & $0 \cdot 48$ & 0.50 \\
\hline At $\mathrm{Vo}_{2} 1.01$ & 0.39 & 0.43 \\
\hline Anaerobic threshold, (AT; 1 ) & 1.37 & 1.53 \\
\hline Delta $\mathrm{V}_{\mathrm{E}} /$ Delta $\mathrm{Vo}_{2}$ (pre-AT) & 40 & 37 \\
\hline Arterial $\mathrm{Po}_{2}(\mathrm{mmHg})$, rest & 92 & 85 \\
\hline Max & 80 & 76 \\
\hline $\mathrm{A}-\mathrm{a} \mathrm{Po}_{2}(\mathrm{mmHg})$, rest & 13 & 8 \\
\hline $\operatorname{Max}$ & 37 & 33 \\
\hline
\end{tabular}

*Values in parentheses are percentages of predicted values 


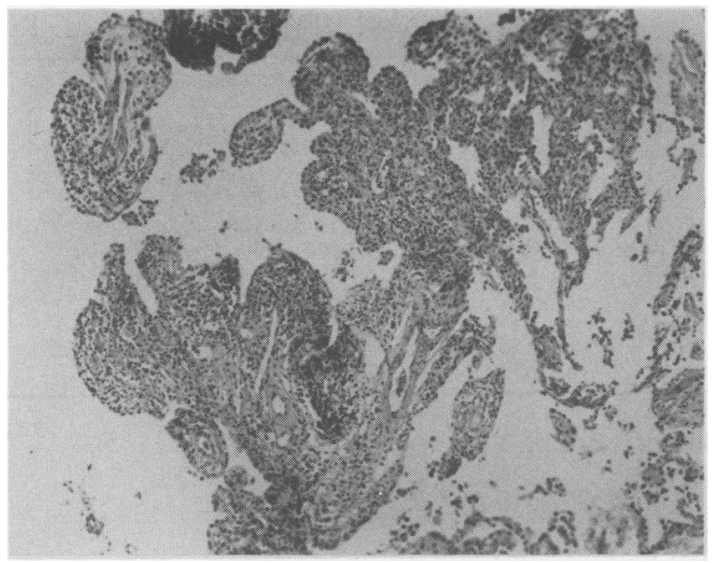

Figure 2 Bronchoscopic biopsy showing marked alveolar septal thickening with diffuse lymphocytic interstitial infiltrate and scattered lymphocytic follicles within septa

(haemotoxylin-eosin stain; original magnification $40 \times$ ).

characteristic of diffuse pulmonary disease (table 2).

Bronchoalveolar lavage results were $45 \times 10^{6}$ cells, $82 \%$ alveolar macrophages, $11 \%$ eosinophils, $5 \%$ polymorphonuclear leucocytes, and $2 \%$ lymphocytes.

Bronchoscopic biopsy performed on 15 October 1985 showed obvious alveolar septal thickening with a diffuse lymphocytic interstitial infiltrate that also formed scattered lymphocytic follicles within septa (fig 2). Germinal centres were not present. There were clusters of macrophages in alveolar spaces. Trichrome stain showed early mild interstitial fibrosis. Neither asbestos bodies nor uncoated fibres were seen. Analytical electron microscopical examination of a carbon extracted biopsy specimen (about $1 \times 2 \times 0.005 \mathrm{~mm}$ ) by the protocol of Langer et al ${ }^{5}$ showed that it contained a variety of mineral dusts,

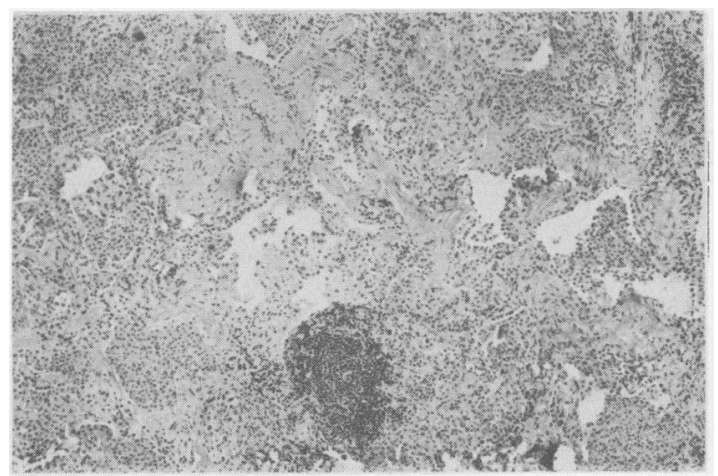

Figure 3 Open lung biopsy of the left upper lobe showing macrophages filling alveolar spaces, septal thickening, and a lymphocytic follicle (haematoxylin-eosin stain; original magnification $40 \times$ ). including both quartz and probably fibrous talc. None of the common asbestos fibres were detected. The report noted that the small size of the specimen placed limitations on any conclusions which might be drawn concerning inorganic agents in the aetiology of DIP.

Open lung biopsy performed on 3 December 1985 (left upper lobe) showed septal thickening and lymphocytic follicles, now with prominent germinal centres (fig 3). Alveolar pneumocytes were hyperplastic, and the intra-alveolar spaces were packed with large macrophages (fig 4) containing vesicular nuclei, some of which had an eosinophilic nuclear inclusion as noted by Pachefsky, et al ${ }^{6}$ in DIP. The macrophage cytoplasm was abundant and eosinophilic and contained granular haemosiderin. On electron microscopy, abundant chrysotile asbestos fibres of $3 \mu \mathrm{m}$ in length were seen within the macrophage cytoplasm (fig 5). A single asbestos body was seen on frozen section (fig 6 ) but none were seen in paraffin sections. Trichrome stain showed mild interstitial fibrosis. The pathological changes were confluent in the subpleural region whereas the central lung tissue was normal in appearance.

Quantitative count of asbestos bodies by phase contrast microscopy on lung tissue digested by the method of Smith and Naylor ${ }^{7}$ gave $4666 / \mathrm{g}$ of wet tissue.

A specimen of bulk wet tissue (about $258 \mathrm{mg}$ ) was digested in $5 \% \mathrm{KOH}$, set in a hot water bath, and prepared for examination by analytical electron microscopy according to the technique outlined in Langer and Nolan. ${ }^{8}$ Mineral fibres were seen in the inorganic residues as follows: chrysotile asbestos, about $819 \times 10^{6}$ fibres/g of dry lung and tremolite, probably as cleavage fragments, about $20 \times 10^{6} / \mathrm{g}$ of dry lung tissue were present. A talc fibre was found and particles of quartz, feldspar, micas, clays, and titanium dioxide were also detected.

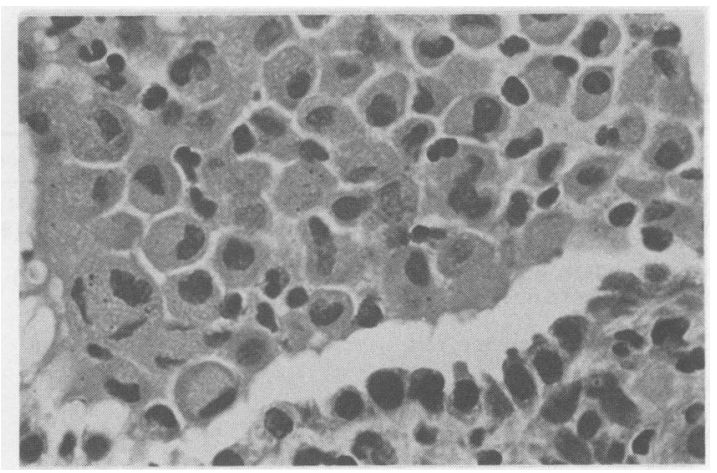

Figure 4 Open lung biopsy of the left upper lobe showing hyperplastic alveolar pneumocytes and macrophages filling the alveolar space (haematoxylin-eosin stain; original magnification $200 \times$ ). 

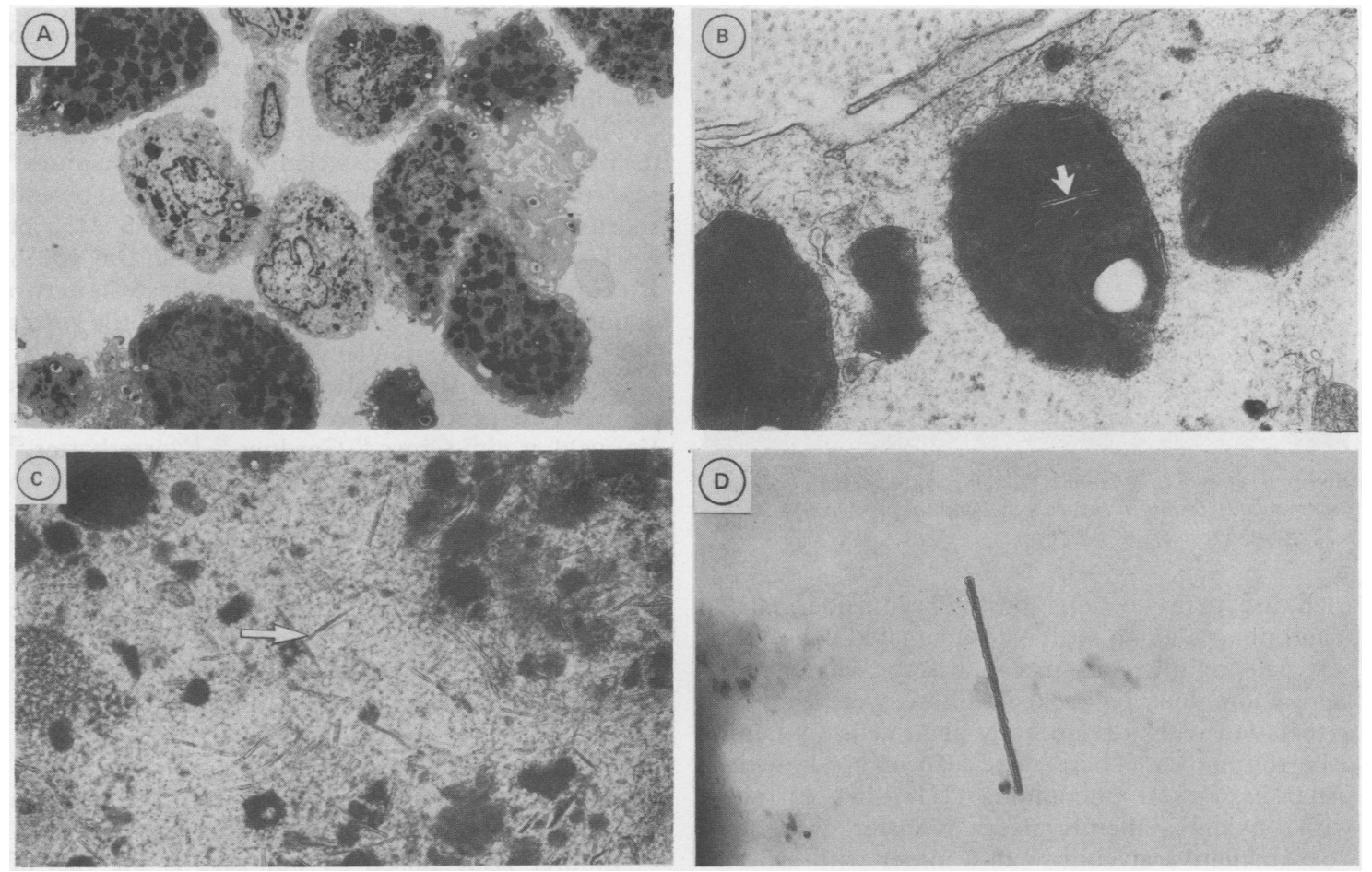

Figure 5 Electron micrographs of interstitial and alveolar macrophages (A) exhibited many of the short fibres in lysosomes (B) (arrow)), and free in the cytoplasm ( (C) arrow). Micrograph (D) shows a typical small fibre from a digested tissue preparation from which the number of fibres and the size were calculated and electron microprobe analysis was performed to document that these were chrysotile fibres. Micrographs (A), B), and (C) are of sections stained with uranyl acetate and lead citrate. $A=1920 \times, B=52000 \times, C=66000 \times, D=40000 \times$.

Some $90 \%$ of the chrysotile fibres were shorter than $5 \mu \mathrm{m}$. Of the 60 grid openings scanned on the grid preparation, and the average number of fibres per grid opening (about 29), it may be extrapolated that asbestos bodies exist in a ratio of less than one in 1740 fibres in the pulmonary tissues. No asbestos bodies were encountered during this scan. The above fibre count is considered conservative in that clumps of chrysotile, consisting of $10 \mathrm{~s}$ to $100 \mathrm{~s}$ of individual fibrils, were counted as single fibres. The size of the chrysotile fibres/fibrils were such as to preclude visualisation by light optical microscopical techniques.

The patient was treated with prednisone $(40 \mathrm{mg} /$ day) with considerable clearing seen on his chest radiograph but no change in his respiratory symptoms or abnormal pulmonary function. The prednisone was tapered after four months and discontinued. The patient noted shortness of breath on bathing and dressing but did not discontinue smoking. The urine sediment showed trace blood, trace protein, 0-2 red blood cells/high power field and 0-2 white blood cells. The cholesterol concentration was lowered to $188 \mathrm{mg} / \mathrm{dl}$ by colestipol.

\section{Discussion}

Desquamative interstitial pneumonia in man has been reported in association with exposure to a variety of agents, including nitrofurantoin ${ }^{9}$ and cobalt in cemented tungsten carbide ${ }^{10}$ and complete Freund's adjuvant in rabbits. ${ }^{11}$ Some cases, showing fibrosis, have had inconsistent immunological abnormalities.$^{10}$ Focal forms have been described.$^{12}$ Some cases arise in association with intercurrent pulmonary disease. ${ }^{13}$ Most cases have been considered idiopathic.

Several reports mention an association between exposure to asbestos and DIP in man. In 1970, Corrin and Price reported a case of DIP in a dock worker in whom infrequent asbestos bodies were found. Asbestos fibres were not mentioned although tissue was examined by electron microscopy. ${ }^{2}$ The patient had antinuclear antibodies in his serum, raising a doubt that his DIP was asbestos related. His disease remitted completely on treatment with corticosteroids. In 1971, Gaensler and Kaplan reported seven patients with asbestos pleural effusions, six of whom had biopsies taken. ${ }^{14}$ They found that, as well as the usual pattern of parenchymal fibrosis seen in 


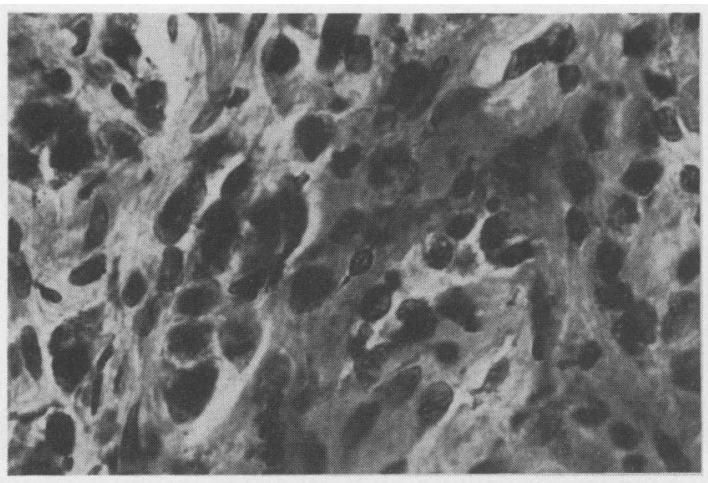

Figure 6 Open lung biopsy, frozen section, showing the sole asbestos body found in this case (haematoxylin-eosin stain; original magnification $400 \times$ ).

each case, many sections showed haemosiderin laden macrophages along with "desquamated cells" densely packing alveolar spaces; in some sections they were more loosely packed. These were found in association with foreign body giant cells containing asbestos bodies. There were also areas showing a usual interstitial pneumonia (UIP)-like histology with hyaline membranes. Webster ${ }^{15}$ reported "desquamative alveolitis" in a miner with asbestos bodies, but the photograph and description suggest UIP, as there was significant interstitial fibrosis as well as partial organisation of alveolar spaces, which contained a few macrophages and (intra-alveolar) asbestos bodies. Thus it seems that only one case of classical DIP associated with exposure to asbestos has been reported in man. ${ }^{2}$ Other cases show a mixed histological pattern of DIP and UIP and some show a predominantly UIP. These reported associations are weakened, however, by the omission of lung tissue analysis to determine mineral dust and asbestos fibre burden.

Animal experiments have occasionally supported an association between DIP and exposure to asbestos. Davis, ${ }^{16}$ before Liebow's initial description of DIP, ${ }^{1}$ reported DIP-like histological findings in rats and guinea pigs inhaling chrysotile asbestos fibres. Although the usual reaction was a fibrosing UIP throughout the lung, in some animals-more frequently in guinea pigs than in rats-portions of lung tissue were completely consolidated, filled with macrophages, lymphocytes, and plasmacytes. In guinea pigs no resolution of the pneumonic process occurred for the five months after stopping inhalation of dust. This did not, however, progress to interstitial fibrosis. In this study, the asbestos fibres were clustered with most fibres being 3-4 $\mu \mathrm{m}$ long. Lemaire et al administered short chrysotile asbestos fibres intratracheally to rats, producing an intraalveolar accumulation of mononuclear cells in small clusters, obliterating alveolar lumina. ${ }^{17}$ Focal septal thickening with a mononuclear cell infiltrate also occurred. Even after two months of exposure, the alveolitis persisted without producing fibrosis.

The fibrogenic potential of short chrysotile asbestos fibres is not entirely settled. In man, Nakamura ${ }^{18}$ reported that asbestos fibres of unspecified type and shorter than $1 \mu \mathrm{m}$ produced asbestosis in $21 \%$ of workers after 5-10 years of exposure and in 100\% after 20 years. Bossard et al reported asbestosis in two of four workers exposed to short chrysotile fibres (90\% less than $2 \mu \mathrm{m}$ in length). ${ }^{19}$

Exposure to short asbestos fibres in animals is reported to produce fibrosis inconsistently. Thus Vorwald et al ${ }^{20}$ Gross, ${ }^{21}$ Gardner, ${ }^{22}$ Klosterkotter, ${ }^{23}$ and Burger and Engelbrecht ${ }^{24}$ reported little or no fibrosis as a result of exposure to short fibres, whereas King et al,${ }^{25} \mathrm{Halt}$ and colleagues, ${ }^{26-28}$ and Hiett et al ${ }^{29} 30$ showed definite pulmonary fibrosis as a result of exposure to these fibres. These variable effects may be the result of different methods of preparing the asbestos fibres, ${ }^{25}$ differences in delivery of the fibre dose to the lung, and species differences in the test animal.

In our case, however, there are sufficient quantities of fibre greater than $5 \mu \mathrm{m}$ in length to act as an agent in the aetiology of any of the asbestos diseases.

Another issue raised by our case is the risk of asbestos disease in drywall workers. The sanding process produces significant numbers of airborne chrysotile asbestos fibres. ${ }^{331}$ Fischbein et al found radiological evidence of asbestosis in $40.9 \%$ of drywall workers. ${ }^{31}$ Interstitial fibrosis was found on a lung biopsy in one drywall worker with lung carcinoma. ${ }^{32}$ As in our case, only ultramicroscopic asbestos fibres were seen. These included both long and short fibres, however.

In summary, the association of DIP with exposure to asbestos in man is not commonly reported. This may be due to the relative infrequency with which cases diagnosed clinically as asbestosis are subjected to biopsy. This case report is the first to document an association between DIP and a heavy occupational exposure to asbestos. Almost 820 million chrysotile fibres/g of dry lung tissue were found, high in the range of values anticipated for occupational exposure. ${ }^{8}$ Importantly, no fibres were visible on light microscopy. We conclude that asbestos should be considered as one of the agents in the aetiology of this case of DIP.

We acknowledge Yasunosuke Suzuki, MD and Irving J Selikoff, MD for their assistance.

Requests for reprints to: $\mathrm{Dr}$ A Miller, Pulmonary Laboratory, Box 1232, Mount Sinai Hospital, One Gustave L. Levy Place, New York, NY 10029, USA. 
1 Liebow AW, Steer, A, Billingsley JG. Desquamative interstitial pneumonia. Am J Med 1965;39:369-404.

2 Corrin B, Price AB. Electron microscopic studies in desquamative interstitial pneumonia associated with asbestos. Thorax 1972;27:324-31.

3 Rohl AN, Langer AM, Selikoff IJ, Nicholson WJ. Exposure to asbestos in use of consumer spackling, patching and taping compounds. Science 1975;189:551-3.

4 Miller A, Thornton JC, Warshaw R, Anderson H, Tierstein AS, Selikoff IJ. Single breath diffusing capacity in a representative sample of the population of Michigan, a large industrial state. Predicted values, lower limits of normal, and frequencies of abnormality by smoking history. Am Rev Respir Dis 1983;127:270-7.

5 Langer AM, Rubin IB, Selikoff IJ, Pooley FD. Chemical characterization of uncoated asbestos fibers from lungs of asbestos workers by electron microprobe analysis. J Histochem Cytochem 1972;20:735-40.

6 Patchesfsky AS, Banner M, Freundlich IM. Desquamative interstitial pneumonia. Significance of intranuclear viral-like inclusion bodies. Ann Intern Med 1971;74:322-7.

7 Smith MJ, Naylor B. A method of extracting ferruginous bodies from sputum and pulmonary tissue. Am J Clin Pathol 1972;58:250-4.

8 Langer AM, Nolan RP. Fiber type and burden found in parenchymal tissues of workers occupationally exposed to asbestos in the United States. In: Bijnon J, Peto J, Saracci R, eds. Non-occupational exposure to mineral fiber. Geneva: International Agency for Research on Cancer, World Health Organisation, 1989:330-5. (Sci. publ. No. 90.)

9 Bone RC, Wolfe J, Sobonya RE, et al. Desquamative interstitial pneumonia following long-term nitrofurantoin therapy. $\mathrm{Am} \mathrm{J}$ Med 1976;60:697-701.

10 Patchefsky AS, Israel HL, Hoch WS, Gordon G. Desquamative interstitial pneumonia. Relationship to interstitial fibrosis. Thorax 1973;28:680-93.

11 Deodhar SD, Bhagwat AG. Desquamative interstitial pneumonia-like syndrome in rabbits. Produced experimentally by Freund's adjuvant. Archives of Pathology. 1976;84:54-8.

12 Kinjo M, Wantanabe $T$, Tanaka $\mathrm{K}$. Localized form of desquamative interstitial pneumonia. Chest 1974;65:458-60.

13 Bedrossian CWM, Kuhn C III, Luna MA, et al. Desquamative interstitial pneumonia-like reactions accompanying pulmonary lesions. Chest 1977;72:166-9.

14 Gaensler EA, Kaplan AI. Asbestos pleural effusion. Ann Intern Med 1971;74:178-91.

15 Webster I. The pathogenesis of asbestosis. In: Shapiro HA, ed. Proceedings of the international conference on pneumoconiosis, Johannesburg. Oxford: Oxford University Press, 1970:117-9.

16 Davis JMG. An electron microscopy study of the effect of asbestos dust on the lung. Br J Exp Pathol 1963;44:454-64.
17 Lemaire I, Nadeau D, Dunnigan J, Masse S. An assessment of the fibrogenic potential of very short $4 \mathrm{~T} 30$ chrysotile by intratracheal instillation in rats. Environ Res 1985;36:314-26.

18 Nakamura I. Clinical and pathological studies of pulmonary asbestosis. Journal of the Nara Medical Association 1967;18:455-65.

19 Bossard E, Stolkin I, Spycher MA, Ruttner JR. Quantification and particle size distribution of inhaled fibres in the lung. International Agency for Research on Cancer, 1980:35-41. (Sci. publ. No. 30.)

20 Vorwald AJ, Durkan TM, Pratt PC. Experimental studies of asbestosis. Archives of Industrial Hygiene and Occupational Medicine 1951;3:1-43.

21 Gross P. Is short fiber asbestos dust a biological hazard? Arch Environ Health 1974;29:115-7.

22 Gardner LU. Silicosis and asbestosis. Lanza AJ, Oxford: Oxford Univ Press, 1938:257.

23 Klosterkotter $\mathrm{W}$. Experimentelle Untersuchungen uber die Beeinflussung der Fibrose durch Polyvinylpyridin-N-Oxid. In: Proceedings, international conference on biological effects of asbestos, Dresden. 1968;47-52.

24 Burger BF, Engelbrecht FM. The biological effects of the international standard reference asbestos samples (UICC) on the lungs of rats. $S$ Afr Med J 1970;44:1271-4.

$25 \mathrm{King}$ EJ, Clegg KW, Rae VM. The effects of asbestos and of asbestos and aluminium on the lungs of rabbits. Thorax 1946;1:188-97.

26 Holt PF, Mills J, Young DK. Experimental asbestosis in the guinea pig. Journal of Pathology and Bacteriology
1966;92:185-95.

27 Holt PF, Mills J, Young DK. The early effects of chrysotile asbestos dust on the rat lung. Journal of Pathology and Bacteriology 1964;87:15-23.

28 Holt PF, Mills J, Young DK. Experimental asbestosis in four types of fiber: Importance of small particles. Ann NYAcad $S_{c i}$ 1965;132:87-97.

29 Hiett DM. Experimental asbestosis: An investigation of functional and pathological disturbances. II. Results for chrysotile exposure. Br J Ind Med 1978;35:135-45.

30 Hiett DM. Experimental asbestosis: An investigation of functional and pathological disturbances. I. Methods, control and exposure conditions. Br J Ind Med 1978;35:129-34

31 Fischbein A, Rohl AN, Langer AM, Selikoff IJ. Drywall construction and asbestos exposure. Am Ind Hyg Assoc J 1979;40:402-7.

32 Fischbein A, Langer AM, Suzuki Y, Selikoff IJ. Carcinoma of the lung in a drywall taping worker. Report of a case. Toxicol Let 1978;2:231-6.

Accepted 12 November 1990 